\section{Processing foreign-accented speech in a second language: Evidence from ERPs during sentence comprehension in bilinguals*}

\author{
SARAH GREY \\ Department of Modern Languages and Literatures, Fordham \\ University \\ LAURA C. SCHUBEL \\ Department of Psychology, George Washington University \\ JAMES M. MCQUEEN \\ Donders Institute for Brain, Cognition, and Behaviour, \\ Radboud University, Max Planck Institute for \\ Psycholinguistics, Nijmegen \\ JANET G. VAN HELL \\ Department of Psychology, The Center for Language Science, \\ Pennsylvania State University
}

(Received: October 9, 2017; final revision received: July 5, 2018; accepted: August 4, 2018)

This study examined electrophysiological correlates of sentence comprehension of native-accented and foreign-accented speech in a second language (L2), for sentences produced in a foreign accent different from that associated with the listeners' L1. Bilingual speaker-listeners process different accents in their L2 conversations, but the effects on real-time L2 sentence comprehension are unknown. Dutch-English bilinguals listened to native American-English accented sentences and foreign (and for them unfamiliarly-accented) Chinese-English accented sentences while EEG was recorded. Behavioral sentence comprehension was highly accurate for both native-accented and foreign-accented sentences. ERPs showed different patterns for L2 grammar and semantic processing of native- and foreign-accented speech. For grammar, only native-accented speech elicited an Nref. For semantics, both native- and foreign-accented speech elicited an N400 effect, but with a delayed onset across both accent conditions. These findings suggest that the way listeners comprehend native-and foreign-accented sentences in their L2 depends on their familiarity with the accent.

Keywords: foreign accent, sentence comprehension, second language, ERPs, grammar, semantics

\section{Introduction}

Listeners and speakers from different language backgrounds interact frequently, and the growing prevalence of multilingualism (Marian \& Shook, 2012) implies that such interactions often involve non-native speakers and listeners. A foreign accent is one of the most salient characteristics of a non-native speaker (Flege, Munro \& MacKay, 1995; Gluszek \& Dovidio, 2010) and foreign-accented speech constitutes an especially challenging example of variability in the speech signal for listeners (Bent \& Holt, 2013; Samuel \& Larraza, 2015). In native (L1) listeners, this variability generally causes comprehension difficulties (Cristia, Seidl, Vaughn, Schmale, Bradlow \& Floccia, 2012; Munro \& Derwing,

\footnotetext{
* This research was supported by NSF SMA-1514276/1659920 to Sarah Grey and Janet G. van Hell and NSF OISE-0968369, NSF BCS 1349110, and OISE 1545900 to Janet G. van Hell. Portions of this research were presented at the 2016 meeting of the Cognitive Neuroscience Society. We thank Courtney Johnson-Fowler, Yiran Zhang, Abigail L. Cosgrove, Carrie Jackson, Kaitlyn Litcofsky, and Tim Poepsel for assistance with this project. We thank Darren Tanner and Katharina Schumann for helpful input on a previous version of the manuscript.
}

1995a, 1995b). The present study investigated the processing of foreign-accented speech in non-native (L2) listeners. Specifically, the study examined processing in bilinguals who listened to sentences in their L2 produced by a native speaker of the target L2 (e.g., native-accented speech) and we compared this with the bilinguals' processing of sentences produced with a foreign accent different from their own foreign accent.

Foreign-accented speech is arguably even more difficult for L2 listeners than for L1 listeners because not only is the speech more variable than canonical (native) speech, but also comprehension is happening in the listeners' L2. Research shows that L2 comprehension of native-accented speech is already a challenging task. For example, L2 phoneme perception is persistently inaccurate and tends to be constrained by the listeners' L1 phonemic inventory (Strange, 1995). Also, studies on word recognition have found that L2 listeners are more susceptible to lexical competition effects than L1 listeners (Weber \& Cutler, 2004).

The general difficulty of speech comprehension in L2 may be attenuated in listening contexts where L2 listeners are processing foreign-accented speech that is congruent with their language background, e.g.,

Address for correspondence:

Sarah Grey, Department of Modern Languages and Literatures, Faber Hall 556, Fordham University, Bronx, NY 10458

sgrey4@fordham.edu 
Chinese L1-English L2 listeners processing ChineseEnglish accented speech, compared to native English accented speech. This attenuation has been termed the Interlanguage Speech Intelligibility Benefit (e.g., Bent \& Bradlow, 2003; Hayes-Harb, Smith, Bent \& Bradlow, 2008; Imai, Walley \& Flege, 2005).

Such work has mainly focused on L2 listeners who are processing speech in native-accented and L1-congruent foreign-accented conditions. Few studies (e.g., Lev-Ari, Heugten \& Peperkamp, 2017; Weber, Di Betta \& McQueen, 2014) have explicitly examined how L2 listeners process foreign-accented speech that is different from (incongruent with) their own L1 background, for example, Dutch L1-English L2 listeners processing Chinese-English accented speech. With increasing globalization and international communication many L2 speaker-listeners process a variety of foreign accents in their daily conversations. More research on the effects of foreign accent incongruence is needed to understand the full range of contexts of speech comprehension in L2 that exist in the real world, including contexts where L2 speakers and listeners do not share an L1 background. Moreover, existing research on speech comprehension in L2 has assessed lexical comprehension (e.g., Hayes-Harb et al., 2008; Larraza, Samuel \& Oñederra, 2016; Xie \& Fowler, 2013) - with little attention paid to sentence-level comprehension, which requires the integration of multiple sources of linguistic information and may show effects distinct from those documented for lexical comprehension. Finally, previous studies have measured only behavioral indices of L2 lexical comprehension of foreign-accented speech, so possible effects of accented speech on the neural correlates of language comprehension in L2 are largely unknown. The current study directly examines L2 sentence comprehension with respect to foreign accent incongruence to shed light on these issues. Specifically, the current study addresses the aforementioned limitations of existing research by examining the neural correlates of sentence comprehension of native- and foreign-accented speech in L2, for L2 listeners who are processing sentences produced in a foreign accent that is different from that associated with their L1, i.e., Dutch L1-English L2 bilinguals who listen to Chinese-accented English sentences.

\section{Event-related potentials and foreign-accented sentence comprehension}

In this study, we used the event-related potential (ERP) technique, which makes it possible to study neural activity associated with sentence processing with millisecond timing precision (for reviews, see e.g., Kaan, 2007; Swaab, Ledoux, Camblin \& Boudewyn, 2012). This study tested grammar and semantic processing during sentence comprehension. ERP research on language often employs a well-established violation paradigm (Kaan, 2007) whereby the electrophysiological brain response to language errors, such as semantic anomalies or grammatical violations, is compared to correct items. This reveals information on the neural correlates of language processing.

In ERP research on language, the P600 is a common ERP effect found in response to violations of L1 grammar (e.g., Osterhout \& Nicol, 1999). P600s are also reliably elicited in L2 speakers, though their elicitation seems to depend on a number of variables, such as L2 proficiency, age of acquisition, and cross-linguistic similarity (for reviews see Morgan-Short, 2014; Van Hell \& Tokowicz, 2010). P600s are characterized by a posterior scalp distribution and tend to occur around 500$800 \mathrm{~ms}$ post-stimulus onset (i.e., after the onset of the target word). The P600 effect is generally accepted as reflecting reanalysis or repair processes during language comprehension (e.g., Kaan, 2007). In the present study, we tested grammatical processing of pronouns, which have elicited P600s in some studies (e.g., Filik, Sanford \& Leuthold, 2008) but in other studies have elicited frontal negativities in the range of $270 \mathrm{~ms}-1500 \mathrm{~ms}$ poststimulus (Grey \& Van Hell, 2017; Nieuwland, 2014). This frontal negativity, called an Nref, is believed to reflect searching in memory for the proper antecedent or attempts at resolving referential ambiguity (e.g., Nieuwland, 2014; Van Berkum, Zwitserlood, Bastiaansen, Brown \& Hagoort, 2004; note that to our knowledge the Nref has not previously been examined in L2 speakers).

With regard to semantic processing, violations of lexical/semantics (such as in example sentence $1 \mathrm{~b}$, see Methods) elicit a centro-parietal negativity around 300$500 \mathrm{~ms}$ post-stimulus, termed the N400 effect. This effect is understood to reflect lexical/semantic access and integration processes (for a review see Kutas \& Federmeier, 2011). While L2 grammar processing (P600s; possible Nrefs) is quite variable regarding whether L2 speakers will show L1-like ERP effects, N400s are commonly observed during L2 semantic processing (for review Bowden, Steinhauer, Sanz \& Ullman, 2013).

It is only within the last 5 years that the well-established ERP correlates of sentence processing have been probed in relation to the potential effects of foreign-accented speech, and this work has only examined L1 processing - that is, a native listener processing native-accented as compared to foreign-accented sentences (Grey \& Van Hell, 2017; Hanulíkova, Van Alphen, Van Goch \& Weber, 2012; Romero-Rivas, Martin \& Costa, 2015, 2016).

Hanulíkova et al. (2012) tested semantic and grammatical processing in native Dutch listeners during comprehension of Dutch sentences that were produced by a native Dutch accented speaker and a foreign TurkishDutch accented speaker. In their study, N400s to semantic 
anomalies were not different in timing or magnitude between native- and foreign-accented speech, though they showed a broader distribution for Turkish-Dutch foreignaccented speech compared to native Dutch-accented speech. For grammatical processing, the authors observed P600s to Dutch agreement errors compared to correct agreement at the beginning of the experiment for only the native-accented condition. There were no ERP effects for foreign-accented grammar errors. Hanulíkova et al. (2012) interpreted the similar N400s in the two accent conditions as evidence that the effect "was not modulated by the accent of the speaker" (p. 884) and that the listeners did not experience comprehension difficulties with the foreign-accented speech. For grammar, Hanulíkova et al. (2012) concluded that the listeners' high familiarity with the Turkish-Dutch foreign accent had led them to adjust their expectations about grammatical well-formedness of Turkish-accented Dutch, since the target error examined in the study is common for Turkish-Dutch L2 speakers. Indeed, when asked to identify the foreign accent at the end of the experiment, more than $80 \%$ of the listeners correctly identified the foreign accent as Turkish.

A recent study by Grey and Van Hell (2017) also tested semantic and grammatical processing in L1 listeners. However, unlike the Hanulíkova et al. listeners, the L1 listeners in Grey and Van Hell (2017) had very little familiarity with the target foreign-accented speech condition (Chinese-accented English). Grey and Van Hell examined the processing of semantic anomalies and pronoun mismatches (i.e., grammar errors) in L1 English listeners during sentence comprehension of native American-English accented speech and foreign ChineseEnglish accented speech. For semantic processing, the authors observed a robust N400 in the native-accented condition, and a reduced and delayed N400 in the foreignaccented condition. For grammar, the results showed an Nref to native-accented pronoun mismatches, but no comparable ERP effects for foreign-accented pronoun mismatches. However, only $30 \%$ of these listeners were able to correctly identify the foreign accent of the study, in stark contrast to the $80 \%$ of listeners in the study by Hanulíkova et al. (2012). When the authors examined the ERP effects in more detail by dividing the L1 listeners into those who could identify the foreign accent and those who could not, a more nuanced pattern emerged for grammar processing. The listeners who could identify the foreign accent indeed showed an ERP response to foreign-accented grammar errors, though rather than an Nref the effect was more similar to an N400 response. The listeners who could not identify the foreign accent $(\sim 2 / 3$ of the sample) showed no ERP effect for grammar. Results for semantic processing did not depend on accent identification. Moreover, behavioral comprehension was similarly high for both sub-groups. These findings indicate that the neural correlates of sentence processing are influenced by foreign-accented speech, and that, especially for grammar, listeners' familiarity with and knowledge about the foreign accent affect sentence processing, at least for listeners who are processing native- versus foreign-accented speech in their native language.

To our knowledge, no study has tested L2 processing of native- as compared to foreign-accented sentences using the ERP technique to assess the effects of accented speech on the neural correlates of sentence comprehension in L2. And as mentioned above, there is very little research, in general, on the effects of foreign accent incongruence on L2 processing, but such research is necessary to elucidate the full range of speech comprehension contexts in L2 that exist in communicative settings in a global society.

In the present study, we gathered ERPs during L2 processing of native- and foreign-accented sentences that were either grammatically and semantically correct, or contained errors in semantics or grammar (further design details are below). We presented these sentences to non-native English listeners (Dutch-English bilinguals) whose accent was incongruent with the target foreignaccented speech condition (Chinese-accented English). For processing of pronouns, if L2 listeners engage similar grammatical processes as L1 listeners, and their processing is not markedly affected by accentedness, then pronoun processing should show an Nref (and/or P600) for native- and foreign-accented sentences. Alternatively, if incongruent foreign-accented speech poses a significant challenge for L2 grammatical processing of pronouns (recall that L2 grammar processing has generally been found to be quite variable; for review, see Van Hell \& Tokowicz, 2010), then L2 listeners may show either no ERP effects for foreign-accented speech or a qualitatively different pattern from native-accented speech, e.g., an N400-like response. For semantics, we predict that L2 listeners engage similar semantic processes as L1 listeners, as has been frequently observed in semantic processing during L2 sentence comprehension; for review, see Bowden et al. (2013). Specifically, L2 listeners are predicted to show N400s for native- and foreign-accented sentences, possibly with similar onsets for both accent conditions (as found by Hanulíkova et al., 2012), or with a delayed onset in the foreign-accented relative to the nativeaccented condition (as found by Grey \& Van Hell, 2017).

\section{Methods}

\section{Participants}

Participants were 39 native Dutch speakers who were highly proficient in L2 English, as assessed by the tests summarized in Table 1. All were students at Radboud University Nijmegen, the Netherlands, a highly multilingual context. Fourteen participants were excluded 
Table 1. Descriptive information on the Dutch-English L2 listeners

\begin{tabular}{lrrc}
\hline \hline$N=25$ & $M$ & $S D$ & $95 \%$ CI \\
\hline AoE to English & 6.44 & 1.92 & {$[5.64,7.20]$} \\
Age of onset of & 10.56 & 1.29 & {$[10.12,11.08]$} \\
$\quad$ English instruction & & & \\
$\quad$ (in years) & & & \\
Years of formal & 8.48 & 1.96 & {$[7.80,9.28]$} \\
$\quad$ English study & & & \\
English verbal fluency & 38.44 & 6.90 & {$[35.88,41.11]$} \\
Dutch verbal fluency & 49.88 & 7.32 & {$[47.04,52.84]$} \\
English MELICET & 42.44 & 3.86 & {$[40.88,43.95]$} \\
$\quad$ score & & & \\
Proficiency self-ratings & & & \\
English speaking & 7.28 & .98 & {$[6.88,7.67]$} \\
English listening & 8.56 & .87 & {$[8.20,8.88]$} \\
English reading & 8.44 & .87 & {$[8.08,8.76]$} \\
English writing & 7.40 & .91 & {$[7.08,7.76]$} \\
Dutch speaking & 9.72 & .46 & {$[9.52,9.88]$} \\
Dutch listening & 9.84 & .37 & {$[9.68,9.96]$} \\
Dutch reading & 9.76 & .44 & {$[9.56,9.92]$} \\
Dutch writing & 9.52 & .59 & {$[9.28,9.72]$} \\
\hline \hline
\end{tabular}

Notes. Values reported are means (M), standard deviations (SD), and [95\% confidence intervals]. AoE $=$ age (in years) of first exposure to English. Verbal fluency represents number of tokens produced in 30 seconds for each of four semantic categories. MELICET $=$ Michigan English Language test, maximum possible score $=50$. Proficiency ratings based on a scale from 1-10 where $10=$ perfect.

from analysis due to excessive artifacts in the raw electroencephalogram (EEG) data (8), technical difficulty with the EEG system (3), or neuropsychological disorder (3). Therefore, data from 25 Dutch-English listeners (mean age: $21.9, S D=5.1 ; 9$ males) were analyzed. None reported a history of learning, hearing, or neuropsychological disabilities and all were right-handed as assessed by an abridged version of the Edinburgh Handedness Inventory (Oldfield, 1971).

\section{Materials}

\section{Stimuli and sentence listening task}

The stimuli were the same as those used in Grey and Van Hell (2017): 240 declarative sentences that were grammatically and semantically well-formed, or matched sentences that had an error either in subject pronouns (he/she; example 1a) or semantics (i.e., were semantically anomalous; example 1b). For a complete list of the sentence stimuli see Appendix A.

(1) a. Grammar: Thomas cooked dinner last night since he/*she was the only person not studying. b. Semantics: Anna stapled the entire stack of papers/*salads together before closing the box.

Subject pronouns were selected as the grammar target because they are a common error in Chinese-English bilinguals (e.g., see grammaticality judgments reported by Johnson \& Newport, 1989), but such errors are uncommon in Dutch-English bilinguals since Dutch and English have comparable pronominal systems (e.g., Van Hell, Verhoeven, Tak \& Van Oosterhout, 2005). All sentences were pre-recorded by two female speakers, one with a standard American-English accent and one with a Chinese-English accent. The speakers were chosen based on accent ratings from a separate group of 32 native English listeners living in the United States. The English accented speaker had a mean accent rating of $1.7(S D=.77)$ on a Likert scale where $1=$ no accent and $7=$ very strong accent; the Chinese-English accented speaker had a mean accent rating of $5.6(S D=.92)$.

During stimulus design, all sentences were normalized for intensity to $75 \mathrm{~dB}$ (see also Note 1). ${ }^{1}$ For the nativeaccented speaker, mean sentence duration was $3234 \mathrm{~ms}$ $(S D=486,95 \%$ CI $[3190,3277])$ and for the foreignaccented speaker mean sentence duration was $4384 \mathrm{~ms}$ $(S D=791,95 \%$ CI $[4313,4455])$. These mean durations were significantly different, $F(1,479)=765.75, p<$ $.001, \eta_{p}^{2}=.62$. For the grammar (pronoun) items, mean native-accented speaker pronoun duration was $117 \mathrm{~ms}$ $(S D=33,95 \%$ CI $[111,123])$ in correct sentences and mean duration in pronoun error sentences was 121 $\mathrm{ms}(S D=35,95 \%$ CI $[115,123])$. Mean foreignaccented speaker pronoun duration was $233 \mathrm{~ms}(S D=82$, $95 \%$ CI $[218,247])$ in correct sentences, and in error sentences was $234 \mathrm{~ms}(S D=79,95 \%$ CI [219, 248]). The results from an ANOVA on durations with Accent (native, foreign) and Well-formedness (correct, error) as withinsubjects factors showed that foreign-accented pronouns were longer in duration than native-accented pronouns (main effect of Accent, $F(1,119)=706.62, p<.001$,

1 The main speech characteristic of interest in this study was speaker accent: native versus foreign. There are of course other variables by which speakers vary, and one of these is pitch. Speakers with higher $F 0$ (fundamental frequency) have been found in behavioral research to be preferred relative to lower $F 0$ speakers, and higher $F 0$ speech may be more salient than lower $F 0$ speech (e.g., Machado, Duarte, Teles, Reis \& Rebelo, 2012; tested native listeners hearing [synthesized] native speech signals). The mean $F 0$ of the native-accented speaker was $192.04(S D=7.95)$ and the mean $F 0$ of the foreign-accented speaker was $196.05(S D=9.27)$. These pitch signals between the two speakers are descriptively highly similar, though the foreign-accented speaker's pitch is higher than the native-accented speaker, $F(1,958)=51.830$, $p<.001$. Considering the aforementioned evidence that listeners may prefer higher-pitched signals and that these tend to be more salient, our results for foreign-accented compared to native-accented speech indicate that foreign accent has quite a powerful effect on processing, since it appears to override pitch signal preferences observed in other research. We thank an anonymous reviewer for raising this point. 
$\left.\eta_{p}^{2}=.85\right)$ with no other significant duration effects (Well-formedness, $p=.698, \eta_{p}^{2}<.01$; Accent $\mathrm{x}$ Wellformedness, $\left.p=.677, \eta_{p}^{2}<.01\right)$.

For the semantic items, spoken word frequency in American English was matched for correct and anomaly words, $F(1,239)=2.03, p=.156, \eta_{p}^{2}=.01$ (correct $M=6008, S D=10805,95 \%$ CI [4257, 8165]; anomaly $M=3922, S D=10796,95 \%$ CI $[2230,6111])$ (Davies, 2008; The Corpus of Contemporary American English). For the native-accented speaker, mean duration for correct semantic items was $326 \mathrm{~ms}(S D=83$, $95 \%$ CI $[312,342])$ and for semantic errors was 387 ms $(S D=91,95 \%$ CI $[371,404])$. For the foreignaccented speaker, mean duration for correct semantic items was $484 \mathrm{~ms}(S D=127,95 \% \mathrm{CI}[461,507])$ and for semantic errors was $557 \mathrm{~ms}(S D=151,95 \%$ CI [530, 584]). An ANOVA with Accent and Well-formedness as within-subjects factors showed that durations for foreign-accented semantic critical items were longer than native-accented semantic items (main effect of Accent $\left.F(1,119)=243.72, p<.001, \eta_{p}^{2}=.67\right)$ and that semantic error items tended to have longer durations than correct items (main effect of Well-formedness $F(1,119)=36.19$, $p<.001, \eta_{p}^{2}=.23$; small effect size) and no other significant duration effects (Accent $\mathrm{x}$ Well-formedness, $\left.p=.548, \eta_{p}^{2}<.01\right)$. The significant differences observed for duration of native- and foreign-accented sentences and items is typical for sentences spoken by native versus non-native speakers and is an inherent aspect of foreignaccented speech (Hanulíkova et al., 2012; Romero-Rivas et al., 2015).

Correct/error and native/foreign accent sentences were distributed across four experimental lists in a Latin-square design. There were 240 sentences in each list, half spoken by the native-accented speaker and half spoken by the foreign-accented speaker. Within each speaker condition for each list, 60 sentences were correct (30 grammar condition, 30 semantics condition), 30 contained the target grammar error, and 30 had a semantic error.

During EEG recording, sentences were presented within the context of a listening task. Participants were informed they were going to listen to two people talk about their friends' lives and were introduced to the names of 10 friends (5 female, 5 male names). No mention was made of accents, grammar, or semantics. Each trial began with a $500 \mathrm{~ms}$ fixation cross in the center of a black screen followed by a sentence delivered bi-aurally using speakers. The fixation remained on screen during the sentence. After the sentence, participants either saw the word "Ready?" or saw a written yes/no comprehension question to which they responded via a button-box. The "Ready?" screen was intended to allow participants to rest their eyes or blink before initiating the next sentence. The questions served to measure comprehension performance and to keep participants alert during the experiment. There were 48 yes/no questions for each list; 24 for each speaker condition (for 12 no and 12 yes responses).

\section{Debriefing survey}

Following the listening task, participants completed a debriefing survey that asked whether they detected a difference in the accent of the two speakers. If they selected 'no' they were prompted to submit the survey. If participants selected 'yes', they were then asked to identify the accent of each speaker. This was a 'free' response, i.e., participants could type any response. Following accent identification, they rated the degree of each accent $(1-7$ rating; $1=$ no accent, $7=$ very strong accent $)$ and how easy it was to understand (1-7 rating; $1=$ very easy to understand, $7=$ very difficult to understand).

\section{Procedure}

After providing informed consent, participants were tested in a single session lasting approximately 2.5 hours. At the beginning of the session, participants completed a background survey that assessed lifelong language experience, neuropsychological background, and sociodemographic information. After this, participants were seated in a comfortable chair in a sound-attenuated room. Participants were read aloud the instructions (in English) of the sentence listening task and completed practice prior to the experimental task. Following EEG recording, participants completed additional tasks including English and Dutch verbal fluency (Luo, Luk \& Bialystok, 2010), and an English grammar test, the MELICET (see Table 1).

\section{EEG acquisition and analysis}

Scalp EEG was recorded at a sampling rate of 1000 $\mathrm{Hz}$ from $32 \mathrm{Ag} / \mathrm{AgCl}$ active electrodes (extended 1020 system; Jasper, 1958) mounted in an elastic cap (Brain Products ActiCap, Germany). EEG was amplified with a Brain Vision BrainAmp system (Brain Products, Germany); it was filtered online with a $.016-250 \mathrm{~Hz}$ bandpass filter and off-line with a $30 \mathrm{~Hz}$ half-amplitude low-pass filter (24dB/octave roll-off). Scalp electrodes were referenced online to a vertex reference and rereferenced off-line to the average of activity from the left and right mastoids. Additional electrodes were placed above and below the left eye and at the outer canthus of each eye, referenced in bipolar montages, in order to monitor ocular movements. Impedances were kept below $10 \mathrm{k} \Omega$.

ERPs were time-locked to the onset of the critical word for each sentence (the bolded words in example 1) and averaged off-line for both linguistic target conditions in each participant (200ms pre-stimulus baseline) within each accent condition. Data free of ocular and muscle 
artifacts were included in the analyses. Informed by previous research and visual evidence from the ERP waveforms, we selected the common time-windows for capturing the ERP effects of interest in this study: Nref, N400, P600. A time-window of $250-500 \mathrm{~ms}$ was selected to capture N400 and Nref effects (e.g., Nieuwland, 2014; Osterhout \& Nicol, 1999) and a time-window of 500$800 \mathrm{~ms}$ was selected due to the sustained character of Nrefs and to capture P600 effects (e.g., Grey, Tanner \& Van Hell, 2017; Grey \& Van Hell, 2017; Nieuwland, 2014), which as reviewed above have occasionally been elicited for pronoun mismatches. Data from the scalp electrodes were grouped into three distributional regions - anterior (Fz, F3, F4, FC5, FC6), central (Cz, $\mathrm{C} 3, \mathrm{C} 4, \mathrm{CP} 1, \mathrm{CP} 2)$, and posterior (Pz, P3, P4, P7, P8) (for similar approaches see Grey et al., 2017; Hanulíkova et al., 2012; Romero-Rivas et al., 2015). Following Grey and Van Hell (2017), mean ERP amplitudes were entered into separate ANOVAs for each time window and linguistic target, with Accent (native, foreign), Well-formedness (correct, error), and Distribution (anterior, central, and posterior) as within-subjects factors. Follow-up analyses were conducted testing a priori hypotheses for the factors Accent and Well-formedness.

\section{Results}

\section{Sentence comprehension}

Listeners showed high comprehension accuracy, $M=.85$, $S D=.07$. Accuracy was high in both the native English and foreign Chinese-English accent conditions $(M=.90$, $S D=.07$ and $M=.81, S D=.11$, respectively), but was significantly higher for native-accented sentences in a twotailed $t$-test by participants and by items $(t 1(24)=4.15$, $p<.001 ; t 2(95)=4.23, p<.001)$.

\section{ERPS}

\section{Grammar}

ERP waveforms for pronoun grammar processing in the native accent and foreign accent conditions are presented in Figures 1 and 2, respectively, and the corresponding topographical voltage maps of both conditions are presented in the top panel of Figure 3. Visual inspection suggested that pronoun mismatches elicited an Nref in the native accent condition (see Figure 1), and no effects in the foreign-accented condition (see Figure 2). The results from the global ANOVA in the $250-500 \mathrm{~ms}$ time window produced no significant main effects or interactions: main effect of Accent, $p=.257$; main effect of Well-formedness, $p=.152$; Accent $\mathrm{x}$ Wellformedness, $p=.182$; Accent $\mathrm{x}$ Well-formedness $\mathrm{x}$ Distribution, $p=.444$. The results from the 500 $800 \mathrm{~ms}$ time-window produced a significant main effect of Accent, $F(1,24)=7.585, p=.011, \eta_{p}^{2}=.24$, due to ERPs in the foreign accent condition being more positive than ERPs in the native accent condition (foreign $M \mu \mathrm{V}=1.327, S E=.320$; native $M \mu \mathrm{V}=.414$, $S E=.188)$, but there were no significant main effects or interactions with Well-formedness (main effect of Well-formedness, $p=.400$, Accent $\mathrm{x}$ Well-formedness, $p=.328$, Accent $\mathrm{x}$ Well-formedness $\mathrm{x}$ Distribution, $p=.714$ ).

To test the a priori hypotheses for differences in native and foreign-accented grammar processing in L2, we also conducted separate analyses within each accent condition for the two time-windows, with Wellformedness and Distribution as within-subjects factors. In the 250-500 ms window, the results showed a main effect for Well-formedness in the native accent condition, $F(1,24)=5.18, p=.032, \eta_{p}^{2}=.18$, as a result of pronoun mismatches (i.e., errors) eliciting more negative ERPs than pronoun matches (native accent mismatch $M \mu \mathrm{V}=.127, S E=.260$; native accent match $M \mu \mathrm{V}=1.044, S E=.304)$. In the foreign accent condition there was no significant main effect of Well-formedness $(p=.821)$ and no interaction with Well-formedness $(p=.915)$. There were no significant main effects or interactions in either accent condition separately in the 500-800 ms window (native accent main effect of Wellformedness, $p=.195$, Well-formedness $\mathrm{x}$ Distribution, $p=.574$; foreign accent main effect of Well-formedness, $p=.805$, Well-formedness $\mathrm{x}$ Distribution, $p=.749$ ).

These analyses confirmed an Nref in the native accent condition, but no significant effect in the foreign accent condition.

\section{Semantics}

ERP waveforms for semantic processing in the native accent and foreign accent conditions are presented in Figures 4 and 5, respectively, and the corresponding voltage maps are presented in the bottom panel of Figure 3. Visual inspection suggests that semantic errors produced an N400 with a delayed onset in both accent conditions (see Figures 4 and 5). ANOVAs confirmed this. In the 250-500 ms time-window, there were no significant effects: main effect of Accent, $p=.829$; main effect of Well-formedness, $p=.650$; Accent $\mathrm{x}$ Well-formedness, $p=.663$; Accent $\mathrm{x}$ Well-formedness $\mathrm{x}$ Distribution, $p=.890$. This indicates there were no differential ERP responses to semantic errors in this timewindow, where N400 effects are commonly observed. This was also the case when each accent condition was analyzed separately (native accent main effect of Wellformedness, $p=.550$, Well-formedness by Distribution, $p=.759$; foreign accent main effect of Well-formedness, $p=.960$, Well-formedness $\mathrm{x}$ Distribution, $p=.495$ ).

In the 500-800 ms time-window there was a significant main effect of Well-formedness, $F(1,24)=7.299$, 

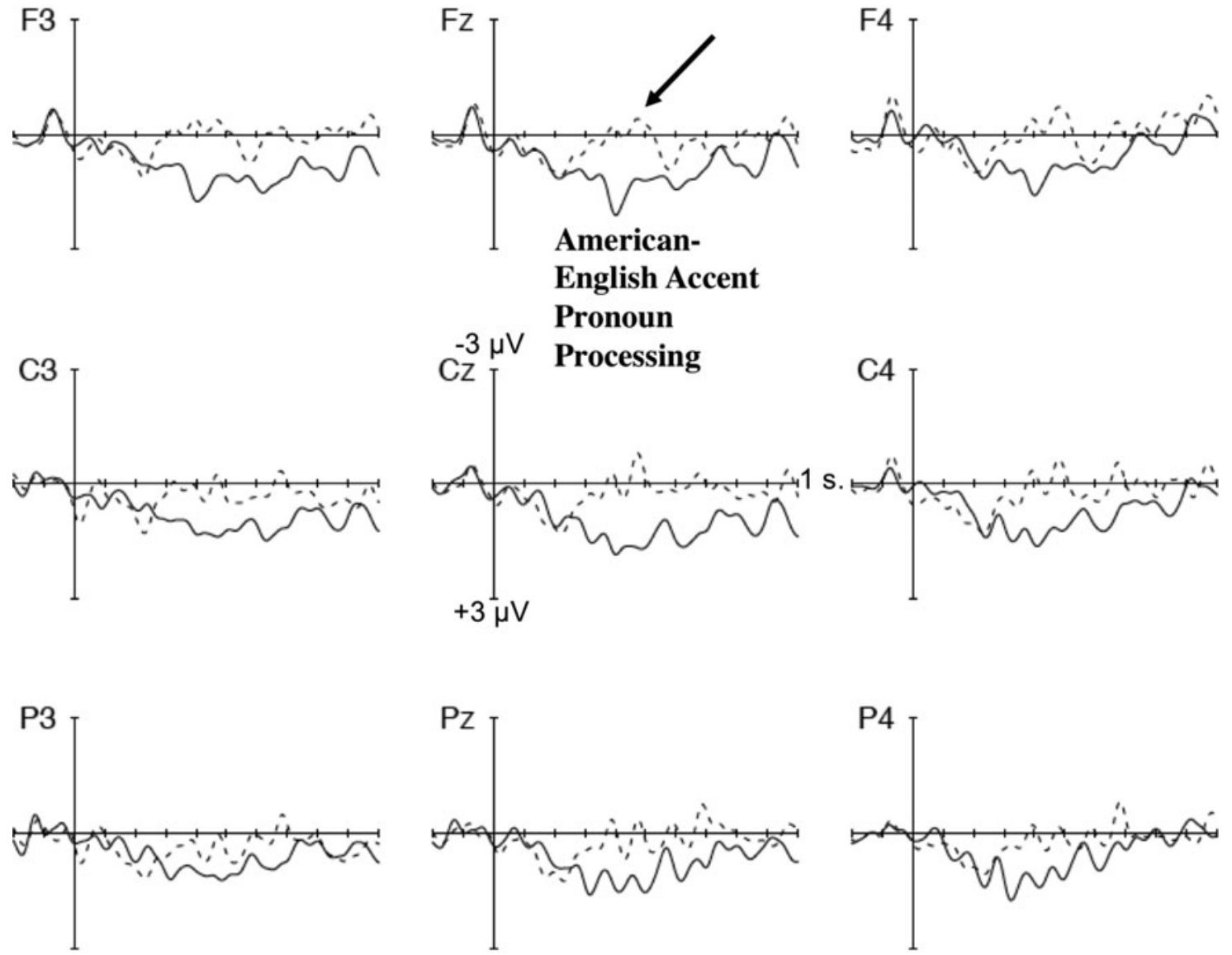

Figure 1. Grand mean ERP waveforms for nine representative electrodes for pronoun processing of native American-English accented speech. Waveforms represent activity for correct pronoun (solid line) and pronoun error (dashed line) conditions. Each tick mark represents $100 \mathrm{~ms}$; negative voltage is plotted up. These and all subsequent waveforms were filtered with a $15 \mathrm{~Hz}$ low-pass filter for presentation purposes only. The black arrow indicates the Nref effect.

$p=.012, \eta_{p}^{2}=.23$, due to semantic errors eliciting more negative ERPs than correct semantics (error $M \mu \mathrm{V}=$ -.644, $S E=.283$; correct $M \mu \mathrm{V}=.217, S E=.202$ ), suggestive of an N400 with a late onset. Semantic errors elicited more negative ERPs than correct semantics for both native-accented and foreign-accented speech in this time window (native accent error $M \mu \mathrm{V}=-.633$, $S E=.388$; native accent correct $M \mu \mathrm{V}=.194, S E$ $=.386$; foreign accent error $M \mu \mathrm{V}=-.655, S E=.329$; foreign accent correct $M \mu \mathrm{V}=.240, S E=.288)$. There was no significant main effect of Accent $(p=.973)$ nor significant interactions with Accent (Accent $\mathrm{x}$ Wellformedness, $p=$.929; Accent $\mathrm{x}$ Well-formedness $\mathrm{x}$ Distribution, $p=.876$ ). Analyses within each accent condition showed that the effect of Well-formedness did not reach significance separately in the two conditions (native accent $p=.126, \eta_{p}^{2}=.095$; foreign accent $p=.064, \eta_{p}^{2}=.14$ ). Thus, over вотн accent conditions, semantic errors elicited a small but significant N400 effect with a delayed onset.

\section{Debriefing}

The debriefing survey revealed that $100 \%$ of the DutchEnglish listeners detected a difference in the accents. The debriefing also showed that many (44\%) of the listeners believed the accents reflected regional or dialect accent differences in English, such as American-English versus Scottish-English, rather than identifying native- versus foreign-accented English. In fact, only 16\% of the listeners differentiated the two accents as representing native versus foreign English and, of those, half (i.e., $8 \%$ of all listeners) correctly identified the Chinese-English accent.

Recall that participants were also asked to provide ratings for the degree of accentedness and comprehensibility of each accent (i.e., how easy it was to understand). As could be expected, the listeners rated the Chinese-English (foreign) accent as having a higher degree of accentedness than the AmericanEnglish (native) accent, $t(24)=6.063, p<.001$ (American-English accent rating $\mathrm{M}=3.04, S D=1.54$; 

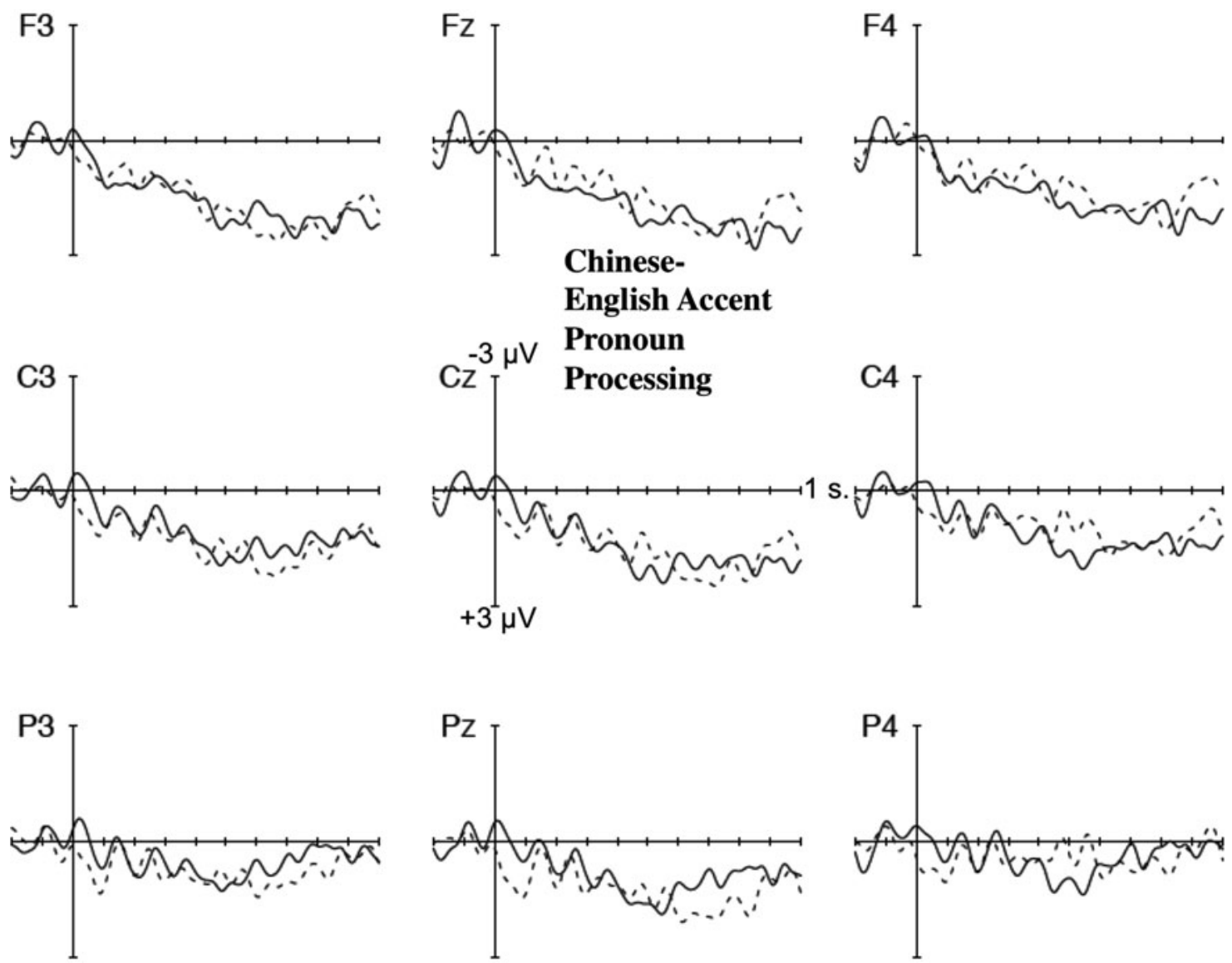

Figure 2. Grand mean ERP waveforms for nine representative electrodes for pronoun processing of foreign Chinese-English accented speech. Waveforms represent activity for correct pronoun (solid line) and pronoun error (dashed line) conditions. Each tick mark represents $100 \mathrm{~ms}$; negative voltage is plotted up.

Chinese-English accent rating $\mathrm{M}=5.68, S D=1.21$ ). The listeners also rated the Chinese-English accent as being less comprehensible than the American-English accent, $t(24)=3.951, p=.001$ (American-English rating $M=2.48, S D=1.81$; Chinese-English accent rating $M=4.68, S D=1.31)$. These ratings reinforce the notion that non-native speech (i.e., the Chinese-English accent tested here) tends to induce intelligibility and comprehension difficulties in listeners (e.g., Munro \& Derwing, 1995a, 1995b), and replicate the debriefing outcomes from the native English listeners tested in Grey and Van Hell (2017).

\section{Discussion}

This study used ERPs to examine neural correlates of L2 processing of grammar and semantics in native- and foreign-accented speech, for a foreign accent that was different from the L2 listeners' own accent in the L2. To our knowledge, this is the first study to examine this issue at the sentence level.
Results for behavioral sentence comprehension showed that the Dutch-English listeners' comprehension accuracy was high for both accent conditions, but they responded more accurately to native American-English accented than to foreign Chinese-English accented sentences. This matches findings that have been observed for native listeners (e.g., Grey \& Van Hell, 2017) and fits with other evidence that foreign-accented speech tends to produce comprehension difficulty (e.g., Munro \& Derwing, 1995a). Considering the high L2 proficiency of the participants (see Table 1), the finding is also in line with recent research showing that, perhaps counterintuitively, greater relative difficulty in understanding foreign-accented speech may be an indicator of higher L2 proficiency, at least for L2 listeners who are processing a foreign accent different from their own (Lev-Ari et al., 2017; note that they tested lexical identification).

The ERP results for grammatical processing showed an Nref effect in response to pronoun mismatches only for the native-accented condition, and not for the foreignaccented condition. From the perspective that Nrefs 


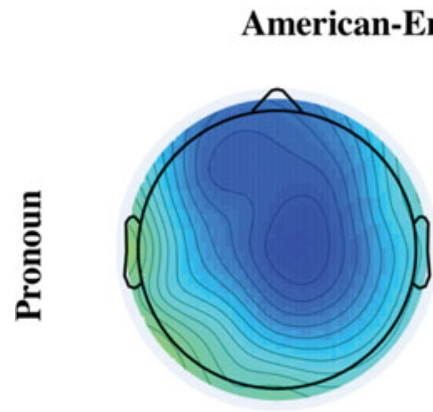

$250-500 \mathrm{~ms}$

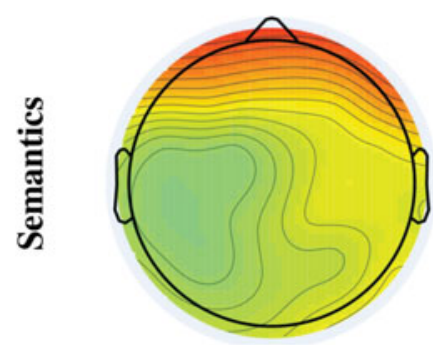

$250-500 \mathrm{~ms}$

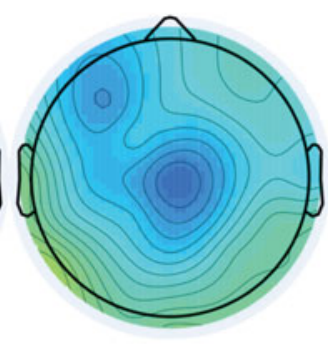

$500-800 \mathrm{~ms}$

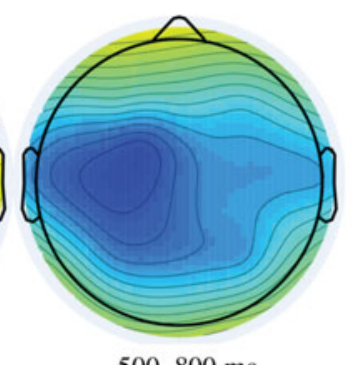

$500-800 \mathrm{~ms}$
Chinese-English Accent
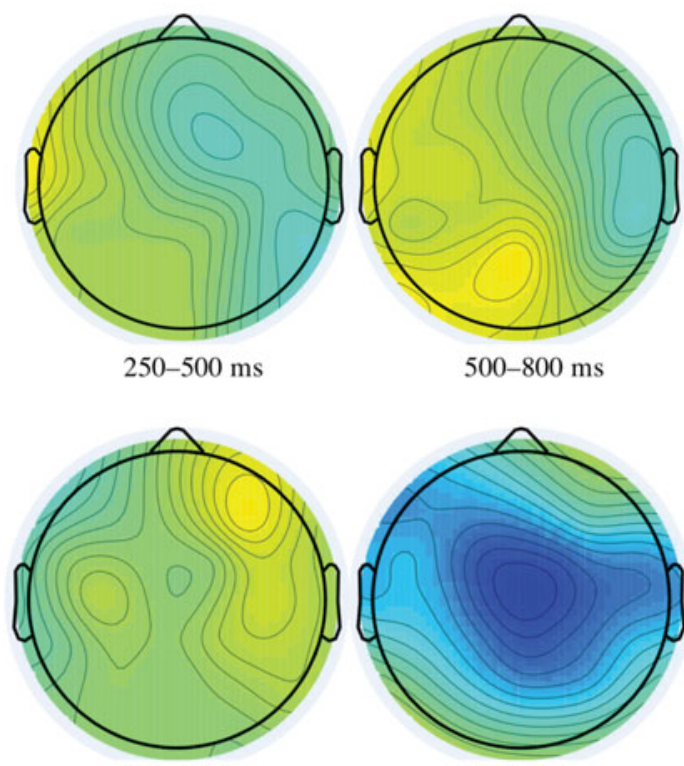

$250-500 \mathrm{~ms}$

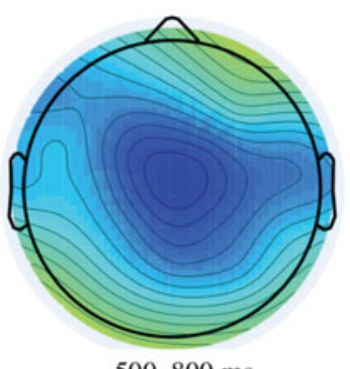

$500-800 \mathrm{~ms}$

Figure 3. (Colour online) Topographical maps show the scalp distribution of activity in the pronoun grammar error minus its matched correct condition and the semantic error minus its matched correct condition for the two accent conditions. Activity is averaged for the $250-500 \mathrm{~ms}$ and $500-800 \mathrm{~ms}$ time windows. Calibration scale is $\pm 2 \mu \mathrm{V}$.

reflect a search in memory for the proper antecedent when the antecedent is missing (e.g., Nieuwland, 2014; Van Berkum, Brown, Hagoort \& Zwitserlood, 2003), the present findings for the L2 listeners indicate that they initiated an antecedent search when encountering the mismatching pronoun in the native-accented L2 sentences, but not in the incongruent foreign-accented L2 sentences. One interpretation of this set of results is that rather than engaging in detailed grammatical processing of the foreign-accented sentences, the L2 listeners employed a 'good enough' processing strategy instead (e.g., Ferreira \& Patson, 2007), which still allowed them to achieve high comprehension accuracy. This 'good enough' processing strategy may have been uniquely cued by the foreign-accented speaker identity (e.g., Bosker, Quené, Sanders \& de Jong, 2014), and notably matches the results observed in L1 listeners in Grey and Van Hell (2017).

ERP research on L2 grammatical processing (mostly focusing on the written modality rather than the auditory modality as tested here) shows that L2 participants are highly variable in whether they show L1-like ERP responses to grammatical violations, often as a function of L2 proficiency (Ojima, Nakata \& Kakigi, 2005), type of language exposure (Batterink \& Neville, 2013; MorganShort, Steinhauer, Sanz \& Ullman, 2012), and crosslanguage similarity (Tolentino \& Tokowicz, 2011). The L2 listeners in this study indeed showed an L1-like ERP pattern for L2 grammar processing as evidenced by the
Nref observed for native-accented speech. Notably, the current results reveal that, within the same group of L2 listeners, incongruent and unfamiliar foreign-accented speech constitutes an important additional source of variability in the elicitation of ERP effects. Future research with other bilingual groups and grammatical targets will help to further generalize, or constrain, the present findings for differential L2 processing of nativeversus foreign-accented grammar during online sentence comprehension. Regarding research with other bilingual groups, it will also be important to consider the influence of L2 immersion. The bilinguals in the present study were tested in an L1 environment and bilinguals who are immersed in the L2 environment may show different results for the processing of native- and (congruent or incongruent) foreign-accented speech.

In contrast to grammar, the results for semantics showed a similar ERP pattern for native- and foreignaccented speech: an N400 effect. However, the N400 component was significantly delayed relative to standard L1 results. It is interesting that the N400 in this study showed a delayed onset but the Nref - found only for the native accent condition - did not. Recall that the pronoun in each sentence was co-indexed (either correctly or incorrectly) with a male or female name introduced at the beginning of the sentence (see example 1a in Methods and Appendix A). One possibility is that this boosted the referential information that could be used by the L2 listeners to process upcoming pronouns during 

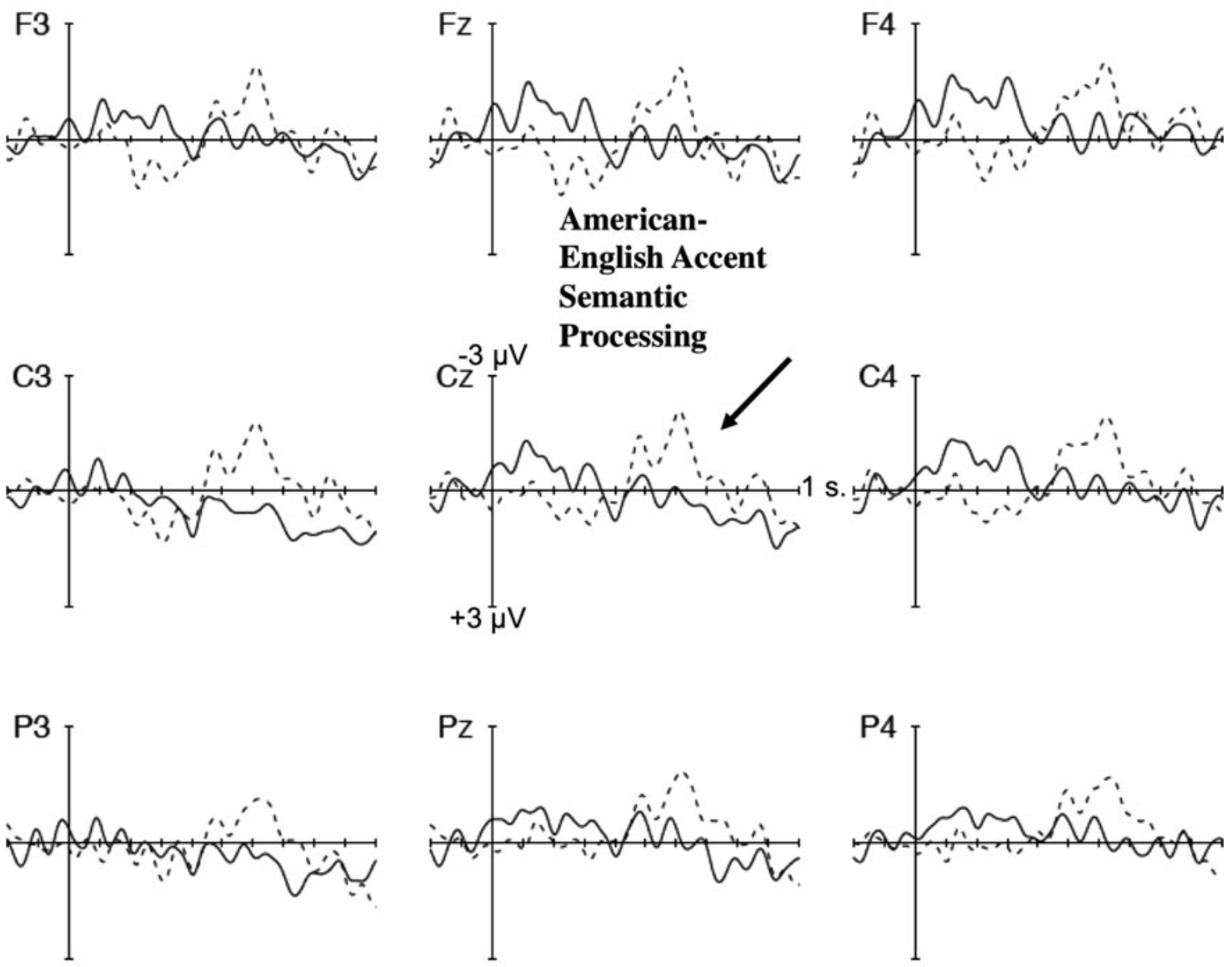

Figure 4. Grand mean ERP waveforms for nine representative electrodes for semantic processing of native American-English accented speech. Waveforms represent activity for correct semantics (solid line) and semantic error (dashed line) conditions. Each tick mark represents $100 \mathrm{~ms}$; negative voltage is plotted up. The black arrow indicates the delayed-onset N400 effect.

sentence comprehension. For example, hearing the name Thomas may have boosted referential information for male pronouns such as he, him, his. This may have made incorrect (mismatching) pronouns even more salient, thus eliciting the Nref, at least for the native-accented speech. Semantics, on the other hand, was not tied to this limited set of grammatical gender information to potentially help boost (or predict) upcoming information that could be useful for listeners during sentence processing. Although one of the primary goals of the study was to test the effects of accent on semantic processing and not, for example, the semantic predictability of sentences, an interesting path for future research would be to examine how variation in the semantic predictability of L2 sentences affects the comprehension of foreign-accented and native-accented speech (see also Schertz \& Hawthorne, 2018).

More generally, the delayed nature of the N400 here aligns with the small amount of ERP research on L2 semantic processing in sentence contexts, which shows that semantic errors tend to elicit N400s that are delayed or reduced in amplitude (for a review see Bowden et al., 2013). Delayed N400 effects may be due to slower or less efficient lexical-semantic processing in the L2 (for discussion, see Mueller, 2005). An alternative interpretation of the delayed negativity is that it is indexing conceptual rather than lexical processing of the semantic error, as suggested by Hahne and Friederici (2001). They hypothesize that the N400 indexes lexical/semantic integration, and that the later negativity indexes that semantic integration processes at the lexical level are supplemented in the L2 by semantic mapping between prior contextual information and the target error at a conceptual level.

The present study examined a further level of L2 semantic processing by investigating the effects of a native and foreign accent on processing. In this context of accented speech and L2 semantic processing, it is of note that the N400 effect was similar across both foreignand native-accented speech conditions. This result makes sense in light of the results for accent identification on the debriefing questionnaire. By and large, the L2 listeners believed they were listening to regional variants of native English, as opposed to native- versus foreign-accented English. In a study with native listeners, Goslin, Duffy, and 

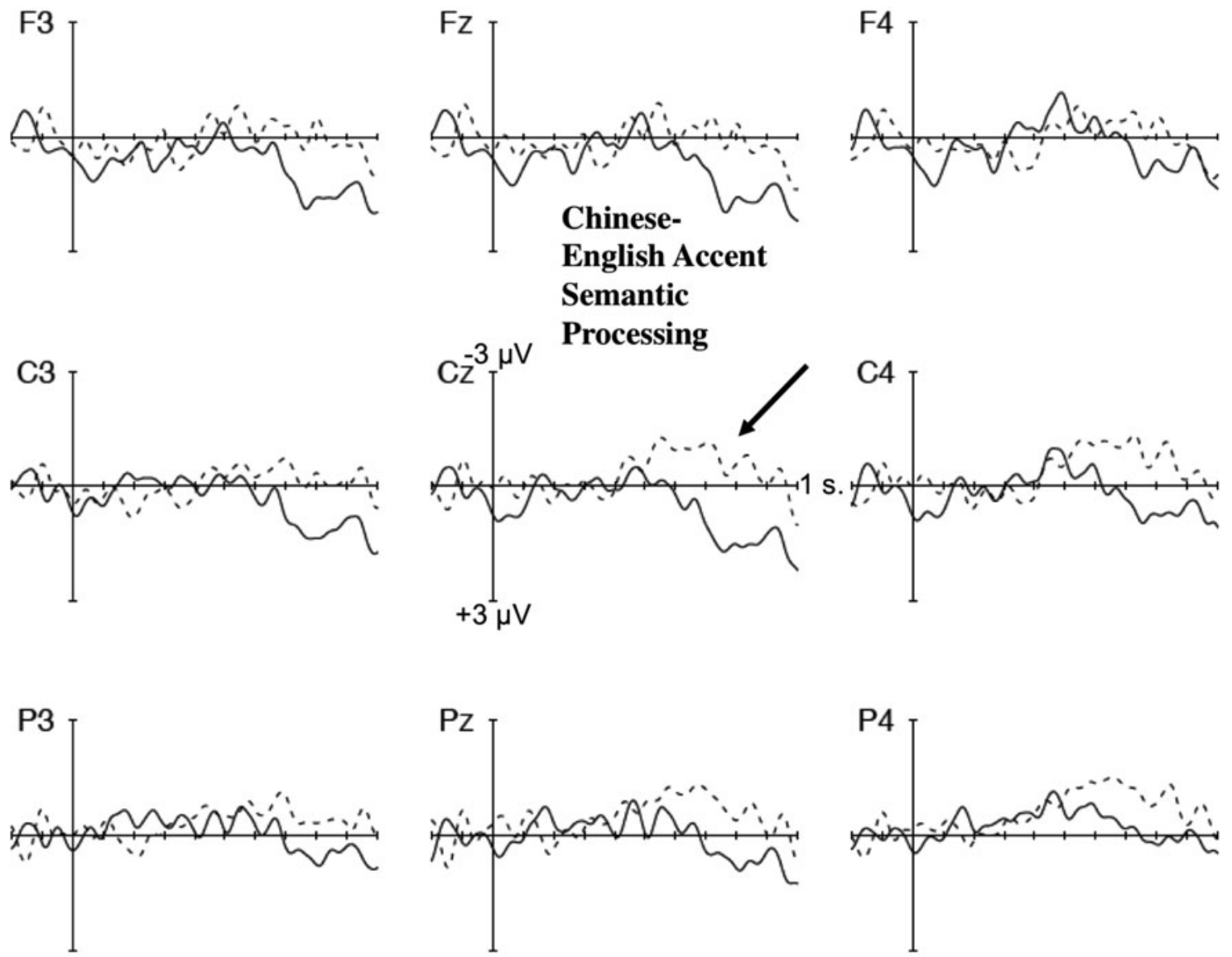

Figure 5. Grand mean ERP waveforms for nine representative electrodes for semantic processing of foreign Chinese-English accented speech. Waveforms represent activity for correct semantics (solid line) and semantic error (dashed line) conditions. Each tick mark represents $100 \mathrm{~ms}$; negative voltage is plotted up. The black arrow indicates the delayed-onset N400 effect.

Floccia (2012) observed similar N400s during semantic processing of different regional accents. Our findings of similar N400s in the present study align well with that work, given that many of the L2 listeners in this study believed they were processing different regional accents. The limited ability of the L2 listeners to identify the accent contrasts with research on L1 listeners, who generally show high ability to distinguish native from foreign accentedness (e.g., Hanulíkova \& Weber, 2012) even if precise identification of the foreign accent is variable among L1 listeners (e.g., Grey \& Van Hell, 2017). However, the present debriefing result aligns well with work on foreign accent perception and intelligibility in L2, which has found that L2 listeners do not uniformly perceive strong accent differences between foreign- and native-accented speech (e.g., Munro, Derwing \& Morton, 2006), especially for accents they are unfamiliar with (e.g., Witteman, Weber \& McQueen, 2013).

The observation that the N400 for semantic processing had a delayed onset, in both native-accented and foreignaccented speech, is also of note. This finding is different from the findings for L1 listeners in Grey and Van Hell
(2017), who were tested on the exact same materials. The L1 listeners in that study showed a delayed N400 to foreign-accented speech, but they showed a classicallytimed N400 for native speech. Linking the results of the current study with prior work suggests that a key factor for the time-course of semantic processing during accented speech comprehension may be FAMILIARITY with the accent, rather than nativeness versus foreignness per se (see also e.g., Larraza \& Best, 2017; Porretta, Tremblay \& Bolger, 2017; Van Heugten \& Johnson, 2014 for recent work on lexical-level processing and accent familiarity). For example, Hanulíkova et al. (2012) observed classically-timed N400s for both native- and foreign-accented semantic processing in L1 listeners who were highly familiar with the foreign accent. Grey and Van Hell (2017) observed classic N400 timing in the native-accented condition in L1 listeners who were explicitly recruited to have limited experience with foreign-accented speech, and the listeners exhibited a delayed N400 for the foreign accent. The debriefing information in the current study showed that most of the L2 listeners thought they listened to regional variants 
of English, which indicates that they were not familiar enough with the distinction between native-accented (American-English) speech and unfamiliar, incongruent foreign-accented (Chinese-English) speech, resulting in the delayed time-course of the N400 observed over both accent conditions.

Another possibility is that although L2 listeners are highly capable of understanding the accented speech, as evidenced by their high comprehension accuracy (similar to L1 listeners confronted with a foreign accent), they are not able to do so in exactly the same way as L1 listeners. Thus, they experience a delayed time-course for semantic processing across both native and foreign accents. Further research on the effects of accentedness and accent familiarity on L2 processing of semantics during sentence comprehension will shed light on these possibilities.

To conclude, the current study's examination of L2 processing of native-accented and unfamiliar foreignaccented sentences provides novel insights into the realtime processing of accented speech in L2 listeners. The study demonstrates differential grammatical processing of native-accented compared with foreign-accented speech (i.e., an Nref vs. no effect) which paralleled ERP results observed in L1 processing (Grey \& Van Hell, 2017). It also demonstrates similar semantic processing in the two accent conditions (delayed N400 in both cases) which differed from results observed in L1 processing of the same sentences (Grey \& Van Hell, 2017). With worldwide multilingualism and increasing globalization, L2 speakerlisteners are frequently in communicative contexts where they are processing a variety of foreign accents. The present findings show that these communicative contexts induce differential patterns of processing for L2 grammar and semantics of native-accented and unfamiliar foreignaccented L2 sentences, and suggest an important role for the L2 listener's familiarity with the accent.

\section{Appendix A}

Sentence stimuli. Target words are in bold, * indicates the pronoun mismatch or semantically anomalous word. See Grey and Van Hell (2017) for further details.

\section{Pronoun}

Peter wanted to skip gym class because he/*she had a hurt ankle.

John was confused about the rent notice because he/*she had already mailed the check.

Thomas was carrying several bottles of water because he/*she would be hiking for a long time.

Richard wanted to wake up early to work out because he/*she knew the meeting would be long.
Kevin thought it had rained because he/*she could see puddles in the yard.

Peter was late for math class because he/*she woke up later than expected.

John had to attend the meeting because he/*she wanted a position on the board.

Thomas thought the race was over because he/*she saw people cheering in the crowd.

Richard borrowed the book from the library because he/*she wanted to read ahead.

Kevin walked to school early because he/*she wanted to avoid the rain.

Peter did not want to cancel the visit to the doctor but he/*she had an exam that day.

John did not wake up early to study but he/*she received a high grade anyway.

Thomas would feel more confident but he/*she received a bad review.

Richard returned the books but he/*she still owed a late fee.

Kevin wanted to travel to Europe but he/*she was not sure there would be time.

Peter wanted to eat dinner but he/*she needed to finish the essay.

John was proud after seeing the test score but he/*she knew it could have been higher.

Thomas was planning to attend the meeting but he/*she missed the bus to school.

Richard normally eats smaller meals but he/*she was very hungry after working out.

Kevin spilled a bowl of soup but he/*she mopped the floor.

Peter won an award at the end of the game since he/*she scored three out of the five goals.

John went to the dentist today since he/*she felt a loose tooth last night.

Thomas went to the mall after class since he/*she wanted to buy new pants.

Richard decided not to go to practice since he/*she was not feeling well.

Kevin went to the car wash since he/*she had the afternoon free.

Peter ran home after band practice since he/*she still had a lot of energy

John did not want to attend social studies since he/*she forgot to finish the homework.

Thomas cooked dinner last night since he/*she was the only person not studying.

Richard had the desk repaired since he/*she knew the owners loved it.

Kevin sat in a desk closer to the front since he/*she forgot to bring glasses.

Peter drank a lot of coffee because he/*she could not stay awake. 
John won the contest because he/*she had a lot of support.

Thomas had trouble following the strict diet because he/*she loved eating ice cream.

Richard likes studying in the morning because he/*she is the only one up at that time.

Kevin played video games all day because he/*she did not have to go to school.

Peter decided to go fishing because he/*she never went as a kid.

John went camping with the family because $\mathbf{h e}^{*} / \mathbf{s h e}$ was going to be in town.

Thomas retook the exam because he/*she did not like the grade.

Richard decided to rent out the apartment because he/*she would be traveling all summer.

Kevin wanted to eat an early lunch because he/*she knew there would not be time later on.

Peter was having trouble seeing but he/*she had just gotten new glasses.

John did not think anyone would attend the ceremony but he/*she saw close friends in the crowd.

Thomas was excited about the concert but he/ ${ }^{*}$ she knew it would take time from his studying.

Richard would have called the hotel but he/*she forgot to charge the phone last night.

Kevin was sick but he/*she decided to play the game anyway.

Peter had a lot of homework but he/*she was still in a very good mood.

John wanted to eat dinner downtown but he/*she could not find the time.

Thomas was supposed to be at the party but he/*she decided to go to the movies.

Richard did not to want attend the show alone but he/*she was the only one free that night.

Kevin wanted to skip the meeting but he/*she had to give a presentation.

John wore contacts today since he/*she had an important interview.

Thomas bought two tickets for the theater since he/*she had a friend visiting.

Richard played the music loud since he/*she had a hearing problem.

Kevin went to bed late since he/*she did not have class in the morning.

Peter went shopping since he/*she needed new clothes and shoes.

John asked for a glass of water since he/*she had eaten a lot of salty popcorn.

Thomas walked to the market since he/*she wanted more exercise.

Richard could not go to the festival since he/* she forgot to buy tickets.
Kevin failed the class since he/*she stopped attending lectures.

John went to the emergency room since he/*she was still feeling sick.

Mary wanted to skip dance class because she/*he had a severe headache.

Emily was worried about the job interview because she/*he still had a sore throat.

Anna was hoping to turn the paper in on time because she/*he needed a good grade.

Kaitlyn wanted to go to sleep early because she/*he had an 8 a.m. workshop.

Megan thought it had rained because she/* he saw water spots on the car.

Mary was worried about the presentation because she/*he was not prepared.

Emily was unsure about the answer because she/*he did not read the textbook.

Anna was excited to check the mail because she/*he was receiving a package today.

Kaitlyn was absent from school because she/*he was sick with the flu.

Megan enjoyed traveling to Europe because she/*he could try new foods.

Mary was excited to go home but she/*he would also miss spending time on campus.

Emily thought the paper was challenging but she/*he agreed the topic was fair.

Anna had planned to wear sandals but she/*he realized it would be rainy.

Kaitlyn was tired of doing homework but she/*he would be too busy to finish tomorrow.

Megan would shop online but she/*he likes to try on the clothes.

Mary did not want to appear on TV but she/*he had agreed to be a guest.

Emily had been optimistic about the exam but she/*he received quite a low score.

Anna normally enjoyed walking home but she/*he was very tired from gym.

Kaitlyn usually liked going to work but she/*he was in trouble with management.

Megan likes the new school but she/*he has trouble passing the exams.

Mary went to the pageant since she/*he wanted to support the girls.

Emily exchanged the gift since she/* he did not like the color.

Anna went to the hospital since she/*he was not feeling well.

Kaitlyn fundraised for the European trip since she/*he could not afford the cost alone.

Megan was sure to be accepted in the program since she/*he met all the criteria. 
Mary slept an extra hour since she/*he did not have class until much later.

Emily was worried about the exam grade since she/*he did not know the answer to several questions.

Anna requested a tutor since she/*he was failing the class.

Kaitlyn played the entire game because she/*he wanted to take the trophy home.

Megan took a long bath since she/*he was sore from practice.

Mary got the answers wrong because she/*he switched the questions around.

Emily decided to lose weight because she/*he wanted to fit in the dress.

Anna did not want to see the movie because she/*he heard it was boring.

Kaitlyn rode the bus to work because she/*he did not want to pay for gas.

Megan studied all night because she/*he had a test the next morning.

Mary ended the relationship because she/*he did not feel good about it anymore.

Emily was fired from the job because she/*he skipped three days of work.

Anna cleaned the house because she/*he wanted to impress everyone.

Kaitlyn disliked going to camp because she/*he did not like the mosquitoes.

Megan apologized to the group because she/*he was wrong about the due date.

Mary knew there were several weeks until the trip but she/*he was already very excited.

Emily lost the keys yesterday but she/*he was able to get in the house.

Anna does not usually take the scenic route but/*he she wanted to see the mountains.

Kaitlyn did not have class in the morning but she/*he woke up early anyway.

Megan does not like cleaning but she/*he will be having visitors tonight.

Mary wanted to finish the marathon but she/*he began to cramp half way through.

Emily was sore from running but she/* he still attended yoga class

Anna was normally confident but she/*he was nervous about the presentation.

Kaitlyn needed a break from work but she/*he could not take a vacation.

Megan could have worked at home but she/*he needed a color printer.

Mary took a different route to school since she/*he wanted a change of scenery.

Emily went to the store since she/*he forgot to buy eggs.
Anna was unable to finish the documentary since she/*he did not pay the internet bill.

Kaitlyn arrived early to the park since she/*he was hosting the yearly picnic.

Megan cooked spaghetti since she/*he had the evening free.

Mary worked extra hours since she/*he needed more money for bills.

Emily was not surprised by the job offer since she/ ${ }^{*}$ he had excellent references.

Anna decided to get a new haircut since she/* he had several upcoming interviews.

Kaitlyn felt left out of the conversation since she/*he had to skip going to the play.

Megan canceled going to camp since she/*he would be taking extra classes.

\section{Semantics}

Mary baked a cake with walnuts and berries/*teacups because it was the teacher's favorite.

Emily has a record marathon time of two hours/*tablecloths and twenty minutes.

Anna was happy she remembered to water the plants/*lamps and flowers before work.

Kaitlyn went on a brisk thirty-minute walk/*pillow every morning last week.

Megan was thirsty and drank a bottle of water $/{ }^{*}$ sand before working out.

Peter had fun on the trip but spent almost a thousand dollars/*puppets on all the food and drinks.

John spent the entire weekend writing thank you cards/*andlesticks to the guests from the party.

Thomas quoted the secretary and the supervisor/

*toothbrush in the weekly project report.

Richard ate a bagel with jelly/*telephone and butter for lunch.

Kevin proclaimed his innocence and denied the lies/* potatoes that had been written about him.

Mary sent two signed copies of the contract/*turtle to the main office.

Emily's wristwatch stopped working and needed batteries/*tomatoes before her vacation.

Anna stapled the entire stack of papers/*salads together before closing the box.

Kaitlyn suspected that the bird food had been eaten by the squirrels/*notebooks that she saw outside last night.

Megan gave the dirty dog a bath/*computer to get rid of the mud.

Peter ate a very spicy taco and his mouth/*trophy was still burning.

John drank an entire bottle/* keyboard of water after his long run. 
Thomas had an interview and made sure to iron the suit/*yogurt before going to sleep.

Richard parked the van/*shampoo near the building entrance.

Kevin loved the band and had heard all of their albums $/{ }^{*}$ pancakes at least twenty times.

Mary was upset with the store and wrote a long email to the manager/*elevator to complain about the clerk.

Emily had lost weight and could wear all of the dresses/*brooms she saw in clothing stores.

Anna helped plant new flowers and bushes/*lipstick in the front and back yard.

Kaitlyn has worked out in the gym five days/*arpets a week since college

Megan needed to know if the pizza sauce had oregano $/{ }^{*}$ mittens in it since she was allergic.

Peter fixed his hair with a comb/*zucchini because it had grown long.

John walked a long way to work/*briefcase in the mornings for exercise.

Thomas read a story/*carrot about a man going on an adventure

Richard planted potatoes/* refrigerators and cabbage in his green house.

Kevin had fun playing on the swingset/*grapefruit and sliding down the slide.

Mary thought it was nice outside and opened the window/* lightbulb to let fresh air in.

Emily crumpled up the latest draft of the essay $/{ }^{*}$ moustache after writing it for hours.

Anna saw the spilled wine and mopped the kitchen/*elephant so nobody would slip.

Kaitlyn raked all the leaves/* pockets in the front yard Wednesday.

Megan was craving Italian food and wanted to eat spaghetti/*driveways for dinner this weekend.

Peter had a thirty-minute break so he walked around the park/*account to get some fresh air.

John swam in the lake/*nickel every day last summer.

Thomas saw the roads were slippery so he gripped the wheel/*bee tightly to avoid losing control.

Richard had a cold and blew his nose/*table with a handkerchief.

Kevin need to tie the wood together so he used a rope $/{ }^{*} \mathbf{z o o}$ that was bought last winter.

Mary listened to the teacher/*napkin lecture about ancient civilizations.

Emily knitted the sweater/*brick with different colors.

Anna framed the photo/* mist and hung it on her living room wall.

Kaitlyn flushed the paperwork down the toilet/*factory by complete accident.

Megan grabbed an envelope and sealed the letter/* fire firmly with wax.
Peter used the knife to spread butter/*magazine on his English muffin.

John spilled a little bit of coffee/*athedral on the brand new carpet.

Thomas felt a terrible amount of pain/*folder in his stomach yesterday.

Kevin tipped the waiter/*volcano twenty percent after paying the bill.

Mary packed the pants and t-shirts/*highway into the suitcase.

Emily went to the hospital/*scarf to visit her grandmother.

Anna diagnosed the child/ ${ }^{*}$ barrel with chicken pox at the hospital.

Kaitlyn traveled across the ocean in a plane/*actus to attend the conference.

Megan likes to sprinkle cashews/*telescopes on her chocolate ice cream.

Peter took his puppy/*ave for a run around the block.

John preheated the oven/*necklace at four hundred degrees.

Thomas zipped up the jacket/*doorknobs because it was very cold outside.

Richard turned on the television*/pistachio to watch his favorite show.

Kevin peeled an apple and a pear/*wagon for the fruit salad.

Mary received a new mitt for Christmas and caught the ball/*igloo in it during baseball practice.

Mary loves peanut butter and jelly/*bookcase sandwiches.

Emily could not golf anymore since she hit the last ball/*shoe into the pond.

Anna went to the beach and now had to wash off the sand $/{ }^{*}$ phone before starting work.

Kaitlyn was having eye trouble from looking at the screen of the computer/*oven all day yesterday.

Megan was babysitting and built a tower of blocks/*jelly that was taller than the couch.

Peter decided to make lemonade and mixed sugar and water $/{ }^{*}$ gravel in the large pitcher.

John put the letter in the mailbox/*water-hose so it would arrive on time.

Thomas tried to pet the barking $\mathbf{d o g} /{ }^{*}$ jeans after playing fetch.

Richard wrapped the present in paper/* milk and many colorful bows.

Kevin cannot eat many fruits like apples/*trees or pears due to an allergy.

Mary put bread in the oven because she enjoyed toast/* piano with jam for breakfast.

Emily played her violin/*window while everyone sang along. 
Anna loves lying in the grass at night and looking up at the stars/*pigs in the clear sky.

Kaitlyn had to squint at the chalkboard after she stepped on her glasses/*cake and broke the lenses.

Megan was yelled at by her parents/ $/{ }^{*}$ glasses for making fun of her sister.

Peter felt sick after eating an entire batch of cookies/*laundry that was meant for the bake sale.

John had nothing to wear because all the clothes/*baseballs were still in the washer.

Thomas felt very hot because he had a fever/*carpet caused by the flu.

Richard was having trouble in class and was sad to receive a bad grade/*sock on the test again.

Kevin was drinking a soda/ ${ }^{*}$ poster and spilled it all over the table.

Kevin spilled paint on the couch and flipped the cushion to hide the stain/* umbrella since it would not wash out.

Mary moisturizes with lotions/*hairclips because her skin is very dry.

Emily gossiped to her friend and started a rumor $/{ }^{*}$ street about a girl in the class.

Anna did not like athletics and her least favorite class was $\mathbf{g y m} /{ }^{*}$ noodle since it involved a lot of sports.

Kaitlyn could not see so she turned on the lights $/{ }^{*}$ shelter to brighten the room.

Megan cut her leg on the nail and put a bandaid/*television on it to stop the bleeding.

Peter was riding his bike when he got a flat tire/*bag and walked the rest of the way.

John received a lot of money for his birthday and deposited it in the bank/*sky to save for a car.

Thomas went to the eye doctor who gave him a new pair of glasses/*gloves so he could see better.

Richard asked his mom to pass the salt and pepper/*house for his meal at dinner.

Kevin did not feel tired but fell asleep on the couch $/{ }^{*}$ ceiling early in the evening.

Mary stopped wearing ponytails because the boys kept pulling her hair ${ }^{*}$ marble in between classes.

Emily added cereal to the bowl and then poured in milk/* money so she could eat breakfast.

Anna watched the couple become husband and wife/* principal during the wedding.

Kaitlyn watched the big storm and heard lots of thunder/*teacher throughout the night.

Megan wore penny loafers with knee-high socks $/{ }^{*}$ kidneys as part of the school uniform.

Peter loves pasta so it is not surprising spaghetti with meatballs $/{ }^{*}$ newspaper is his favorite meal.

John was eating pizza and poured a big glass of soda $/{ }^{*}$ ham to drink with the snack.

Thomas did not like healthy food so he rarely bought fruits or vegetables/*boxes at the grocery store.
Richard washed the mud from his hands with hot water and soap/*brick in the kitchen sink.

Kevin made two hotdogs and put ketchup and mustard $/{ }^{*}$ mermaid on both for dinner.

Mary always listened to loud music/*orange even though it gave her mom headaches.

Emily loved going to the pet store because it was filled with animals/*sidewalks to play around with.

Anna asked her teacher to line the boys up in the front and the girls/*tubas in the back today.

Kaitlyn wore rings on each of her fingers/*hamburgers to campus every day.

Megan used to love visiting the farm and helping milk the cows $/{ }^{*}$ pillows a few days each month.

Peter microwaved the leftover food/*crayon at work for lunch.

John scraped the icing off the birthday cake/* soccer because he did not like chocolate.

Thomas visited the beach and swam in the ocean/*closet during the long weekend break.

Richard hates the cold so his favorite season is summer/*broccoli since the weather is warm.

Kevin took the clothes out of the washer and put them in the dryer/*diary so he could finish his laundry.

Mary watched the spider build a web/*window so it could catch flies.

Emily does not like needles so she tried to hide when the doctor ${ }^{*}$ poodle walked in the examination room.

Anna finished reading the book and returned it to the library $/{ }^{*}$ strawberry to avoid paying a fee.

Kaitlyn swam in the pool/*needle to keep cool in the summer.

Megan turned on the radio so she could listen to music/*bench while she was in the car.

Peter wanted to play soccer but it had rained and the field $/{ }^{*}$ pencil was still too muddy.

John liked to shop at different stores/*candles and visited the mall often.

Thomas wrote an email/*eraser to the president of the club.

Richard studies late in the library $/{ }^{*}$ juice for his final exam.

\section{References}

Batterink, L., \& Neville, H. (2013). Implicit and explicit second language training recruit common neural mechanisms for syntactic processing. Journal of Cognitive Neuroscience, 25(6), 936-951.

Bent, T., \& Bradlow, A. R. (2003). The interlanguage speech intelligibility benefit. The Journal of the Acoustical Society of America, 114, 1600.

Bent, T., \& Holt, R. F. (2013). The influence of talker and foreign-accent variability on spoken word identification. 
The Journal of the Acoustical Society of America, 133(3), 1677-1686.

Bosker, H. R., Quené, H., Sanders, T., \& de Jong, N. H. (2014). Native 'um's elicit prediction of low-frequency referents, but non-native 'um's do not. Journal of Memory and Language, 75, 104-116.

Bowden, H. W., Steinhauer, K., Sanz, C., \& Ullman, M. T. (2013). Native-like brain processing of syntax can be attained by university foreign language learners. Neuropsychologia, 51(13), 2492-2511.

Cristia, A., Seidl, A., Vaughn, C., Schmale, R., Bradlow, A., \& Floccia, C. (2012). Linguistic processing of accented speech across the lifespan. Frontiers in psychology, 3.

Davies, M. (2008) The Corpus of Contemporary American English: 520 million words, 1990-present. Available online at http://corpus.byu.edu/coca/.

Ferreira, F., \& Patson, N. D. (2007). The 'good enough'approach to language comprehension. Language and Linguistics Compass, 1(1-2), 71-83.

Filik, R., Sanford, A. J., \& Leuthold, H. (2008). Processing pronouns without antecedents: Evidence from event-related brain potentials. Journal of Cognitive Neuroscience, 20(7), 1315-1326.

Flege, J. E., Munro, M. J., \& MacKay, I. R. A. (1995). Factors affecting strength of perceived foreign accent in a second language. The Journal of the Acoustical Society of America, 97(5), 3125-3134.

Gluszek, A., \& Dovidio, J. F. (2010). The way they speak: A social psychological perspective on the stigma of nonnative accents in communication. Personality and Social Psychology Review, 14(2), 214-237.

Goslin, J., Duffy, H., \& Floccia, C. (2012). An ERP investigation of regional and foreign accent processing. Brain and Language, 122(2), 92-102.

Grey, S., Tanner, D., \& Van Hell, J. G. (2017). How right is left? Handedness modulates neural responses during morphosyntactic processing. Brain Research, 1669, 27-43.

Grey, S., \& Van Hell, J. G. (2017). Foreign-accented speaker identity affects neural correlates of sentence comprehension. Journal of Neurolinguistics, 42, 93-108.

Hahne, A., \& Friederici, A. D. (2001). Processing a second language: Late learners' comprehension mechanisms as revealed by event-related brain potentials. Bilingualism: Language and Cognition, 4, 123-141.

Hanulíkova, A., van Alphen, P. M., van Goch, M. M., \& Weber, A. (2012). When one person's mistake is another's standard usage: The effect of foreign accent on syntactic processing. Journal of Cognitive Neuroscience, 24(4), 878-887.

Hanulíkova, A., \& Weber, A. (2012). Sink positive: Linguistic experience with th substitutions influences nonnative word recognition. Attention, Perception, \& Psychophysics, 74(3), 613-629.

Hayes-Harb, R., Smith, B. L., Bent, T., \& Bradlow, A. R. (2008). The interlanguage speech intelligibility benefit for native speakers of Mandarin: Production and perception of English word-final voicing contrasts. Journal of phonetics, 36(4), 664-679.

Imai, S., Walley, A. C., \& Flege, J. E. (2005). Lexical frequency and neighborhood density effects on the recognition of native and Spanish-accented words by native English and Spanish listeners. The Journal of the Acoustical Society of America, 117(2), 896-907.

Johnson, J. S., \& Newport, E. L. (1989). Critical period effects in second language learning: The influence of maturational state on the acquisition of English as a second language. Cognitive Psychology, 21(1), 60-99.

Kaan, E. (2007). Event-related potentials and language processing: A brief overview. Language and Linguistics Compass, 571-591.

Kutas, M., \& Federmeier, K. D. (2011). Thirty years and counting: Finding meaning in the the N400 component of the event-related brain potential Annual Review of Psychology, 62, 621-647.

Larraza, S., Samuel, A. G., \& Oñederra, M. L. (2016). Listening to accented speech in a second language: First language and age of acquisition effects. Journal of Experimental Psychology: Learning, Memory, and Cognition, 42(11), 1774.

Larraza, S., \& Best, C. T. (2017). Differences in phonetic-tolexical perceptual mapping of $\mathrm{L} 1$ and $\mathrm{L} 2$ regional accents. Bilingualism: Language and Cognition, 1-21.

Lev-Ari, S., Heugten, M., \& Peperkamp, S. (2017). Relative difficulty of understanding foreign accents as a marker of proficiency. Cognitive Science, 41(4), 11061118 .

Luo, L., Luk, G., \& Bialystok, E. (2010). Effect of language proficiency and executive control on verbal fluency performance in bilinguals. Cognition, 114, 29-41.

Machado, S., Duarte, E., Teles, J., Reis, L., \& Rebelo, F. (2012). Selection of a voice for a speech signal for personalized warnings: The effect of speaker's gender and voice pitch. Work, 41(Supplement 1), 3592-3598.

Marian, V., \& Shook, A. (2012). The cognitive benefits of being bilingual. Paper presented at the Cerebrum: the Dana forum on brain science.

Morgan-Short, K. (2014). Electrophysiological approaches to understanding second language acquisition: A field reaching its potential. Annual Review of Applied Linguistics, 34, 15-36.

Morgan-Short, K., Steinhauer, K., Sanz, C., \& Ullman, M. T. (2012). Explicit and implicit second language training differentially affect the achievement of native-like brain activation patterns. Journal of Cognitive Neuroscience, 24(4), 933-947.

Mueller, J. L. (2005). Electrophysiological correlates of second language processing. Second Language Research, 21(2), $152-174$.

Munro, M. J., \& Derwing, T. M. (1995a). Foreign accent, comprehensibility, and intelligibility in the speech of second language learners. Language Learning, 45(1), 7397.

Munro, M. J., \& Derwing, T. M. (1995b). Processing time, accent, and comprehensibility in the perception of native and foreign-accented speech. Language and Speech, 38(3), 289-306.

Munro, M. J., Derwing, T. M., \& Morton, S. L. (2006). The mutual intelligibility of L2 speech. Studies in Second Language Acquisition, 28(1), 111-131. 
Nieuwland, M. S. (2014). "Who's he?" Event-related brain potentials and unbound pronouns. Journal of Memory and Language, 76, 1-28.

Ojima, S., Nakata, H., \& Kakigi, R. (2005). An ERP study on second language learning after childhood: Effects of proficiency. Journal of Cognitive Neuroscience, 17(8), 1212-1228.

Oldfield, R. C. (1971). The assessment and analysis of handedness: The Edinburgh inventory. Neuropsychologia, 9(1), 97-113.

Osterhout, L., \& Nicol, J. (1999). On the distinctiveness, independence, and time course of the brain responses to syntactic and semantic anomalies. Language and Cognitive Processes, 14(3), 283-317.

Porretta, V., Tremblay, A., \& Bolger, P. (2017). Got experience? PMN amplitudes to foreign-accented speech modulated by listener experience. Journal of Neurolinguistics, 44, 54-67.

Romero-Rivas, C., Martin, C. D., \& Costa, A. (2015). Processing changes when listening to foreign-accented speech. Frontiers in human neuroscience, 9.

Romero-Rivas, C., Martin, C. D., \& Costa, A. (2016). Foreign-accented speech modulates linguistic anticipatory processes. Neuropsychologia, 85, 245-255.

Samuel, A. G., \& Larraza, S. (2015). Does listening to non-native speech impair speech perception? Journal of Memory and Language, 81, 51-71.

Schertz, J., \& Hawthorne, K. (2018). The effect of sentential context on phonetic categorization is modulated by talker accent and exposure. The Journal of the Acoustical Society of America, 143(3), EL231-EL236.

Strange, W. (1995). Speech perception and linguistic experience: Issues in cross-language research: York Press.

Swaab, T. Y., Ledoux, K., Camblin, C. C., \& Boudewyn, M. A. (2012). Language-related ERP components. Oxford handbook of event-related potential components, 397-440.

Tolentino, L., \& Tokowicz, N. (2011). Across language, space, and time: A review of the role of cross-language similarity in L2 (morpho)syntactic processing as revealed by fMRI and ERP methods. Studies in Second Language Acquisition, 33, 91-125.

Van Berkum, J. J. A., Brown, C. M., Hagoort, P., \& Zwitserlood, P. (2003). Event-related brain potentials reflect discoursereferential ambiguity in spoken language comprehension. Psychophysiology, 40(2), 235-248.

Van Berkum, J. J. A., Zwitserlood, P., Bastiaansen, M. C. M., Brown, C. M., \& Hagoort, P. (2004). So who's" he" anyway? Differential ERP and ERSP effects of referential success, ambiguity and failure during spoken language comprehension. Supplement to the Journal of Cognitive Neuroscience, 16, 70.

van Heugten, M., \& Johnson, E. K. (2014). Learning to contend with accents in infancy: Benefits of brief speaker exposure. Journal of Experimental Psychology: General, 143(1), 340.

Van Hell, J. G., \& Tokowicz, N. (2010). Event-related brain potentials and second language learning: Syntactic processing in late L2 learners at different L2 proficiency levels. Second Language Research, 26(1), 43-74.

Van Hell, J. G., Verhoeven, L., Tak, M., \& van Oosterhout, M. (2005). To take a stance: A developmental study of the use of pronouns and passives in spoken and written narrative and expository texts in Dutch. Journal of Pragmatics, 37(2), 239-273.

Weber, A., \& Cutler, A. (2004). Lexical competition in nonnative spoken-word recognition. Journal of Memory and Language, 50(1), 1-25.

Weber, A., Di Betta, A. M., \& McQueen, J. M. (2014). Treak or trit: Adaptation to genuine and arbitrary foreign accents by monolingual and bilingual listeners. Journal of Phonetics, 46, 34-51.

Witteman, M. J., Weber, A., \& McQueen, J. M. (2013). Foreign accent strength and listener familiarity with an accent codetermine speed of perceptual adaptation. Attention, Perception, \& Psychophysics, 1-20.

Xie, X., \& Fowler, C. A. (2013). Listening with a foreign-accent: The interlanguage speech intelligibility benefit in Mandarin speakers of English. Journal of Phonetics, 41(5), 369-378. 